\title{
Morpholino-Substituted BODIPY Species: Synthesis, Structure and Electrochemical Studies
}

\author{
Hawazen Hassanain ${ }^{1,2}{ }^{\circledR}$, E. Stephen Davies ${ }^{1}$, William Lewis $\left.{ }^{1}{ }^{(}\right)$, Deborah L. Kays ${ }^{1, *}$ and \\ Neil R. Champness ${ }^{1, *}$ \\ 1 School of Chemistry, University of Nottingham, University Park, Nottingham NG7 2RD, UK; \\ hmhassanain@uj.edu.sa (H.H.); Pczesd@exmail.nottingham.ac.uk (E.S.D.); w.lewis@sydney.edu.au (W.L.) \\ 2 Department of Chemistry, College of Science, University of Jeddah, P.O. BOX 34, Jeddah 21959, Saudi Arabia \\ * Correspondence: Deborah.Kays@nottingham.ac.uk (D.L.K.); neil.champness@nottingham.ac.uk (N.R.C.)
}

Received: 23 December 2019; Accepted: 11 January 2020; Published: 14 January 2020

\begin{abstract}
Functionalization of 4,4-difluoro-4-bora-3a,4a-diaza-s-indacene (BODIPY) chromophores at the 2,6-positions with iodo substituents and morpholino-substituted $\alpha$-methyl groups affords molecules with strong absorbance in the visible spectrum. The effect of such substitution on the solid-state arrangements, absorption, fluorescence and electronic properties of these dye molecules is reported. The spectroscopic and spectroelectrochemical measurements display intense absorptions in the UV-visible spectrum with bathochromic shifts, in comparison to unfunctionalized BODIPY, and a positive shift in redox potentials due to functionalisation of the BODIPY core. Halogen bonds are observed in the solid-state structures of both halogenated BODIPY species, which in one case leads to the formation of an unusual halogen bonded framework.
\end{abstract}

Keywords: boron-dipyrromethene dye; halogen bonding; polymorphism; Hirshfeld surface analysis; spectroelectrochemistry

\section{Introduction}

BODIPY (4,4-difluoro-4-bora-3a,4a-diaza-s-indacene) compounds are a class of dye molecules that have been investigated extensively because of their applications in biology, materials and supramolecular chemistry [1-4]. The robust nature of the compounds and their attractive photochemical properties have led to their use for various applications [1,2,4] including light-harvesting devices [4,5], solar cell technology $[4,6,7]$ and chemical sensors [8]. In order to develop specifically targeted BODIPY compounds modification of the dipyrrin core is required. Introduction of different substituents can significantly affect the optical behaviour of BODIPY species, for example heavy atoms, such as iodine, can favour the generation of triplet states [9,10], whereas other substituents, such as amines [11-15] can significantly alter the orbital energy manifold and quench fluorescence even when not conjugated with the dipyrrin core [11].

Perhaps the most widely known strategy for BODIPY post-functionalization is halogenation. Halogenation offers both the possibility of directly modifying the BODIPY properties, due to the introduction of halogen substituents, but also raises the possibility of subsequent reactions to introduce further functionality [16-22]. In this study we demonstrate the extension of these strategies using BODIPY analogues to functionalise $\alpha$-methyl groups whilst also halogenating unsubstituted $\beta$-positions using direct electrophilic halogenation [4]. By using this simple approach, we were able to combine different functionalities in a single BODIPY molecule. In particular, our aim was to investigate the effect of combining halo-functionalisation at $\beta$-positions with non-conjugated tertiary amine substitution of the $\alpha$-methyl groups on the absorption and electronic properties of BODIPY species. Thus, we have identified three target BODIPY molecules, 1,3,5,7-tetramethyl-8-phenyl-4,4-difluoroboradiazaindacene 
(1), 2,6-diiodo-1,3,5,7-tetramethyl-8-phenyl-4,4-difluoroboradiazaindacene (2) and 2,6-diiodo5,7-dimethyl-1,3-bis (methylene) dimorpholino-8-phenyl-4,4-difluoroboradiazaindacene (3) (Scheme 1), which are studied herein.

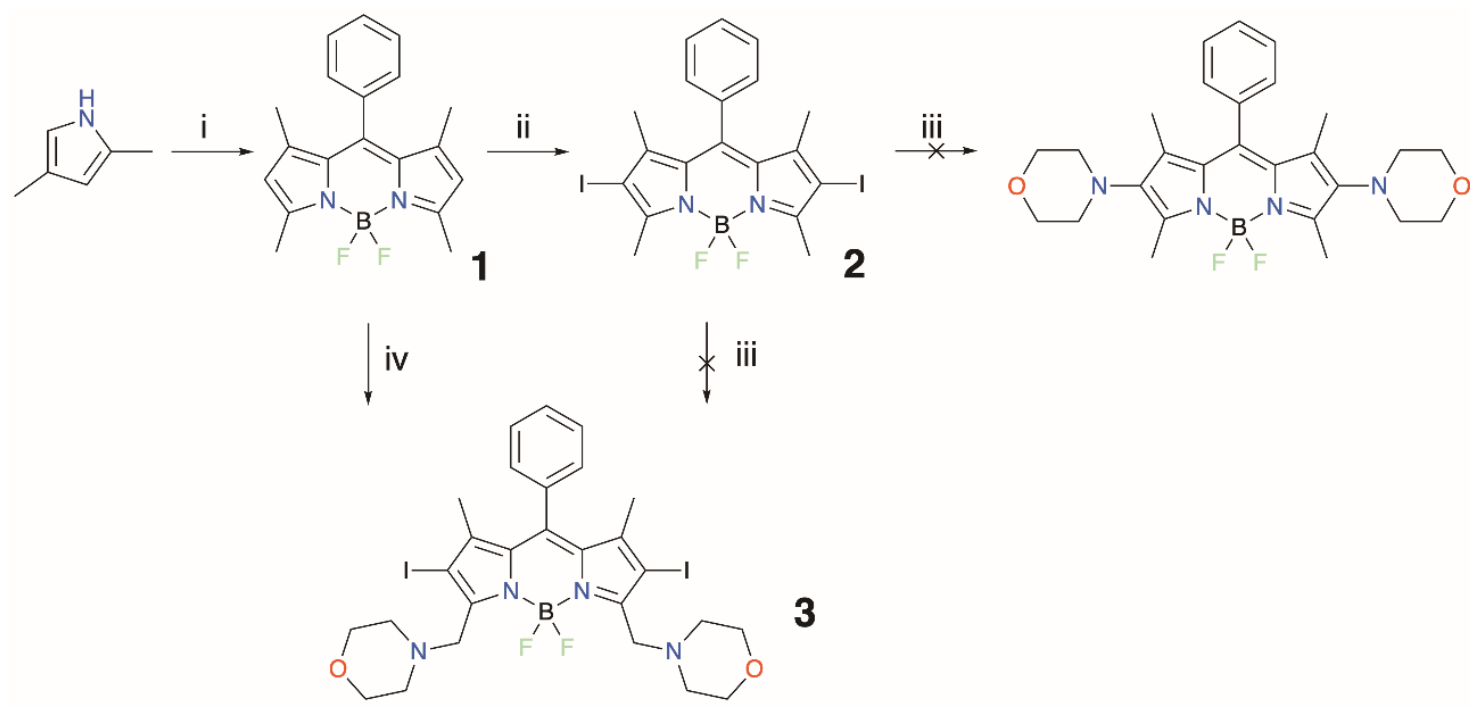

Scheme 1. Synthesis of compounds 1-3. (i) benzoyl chloride, $\mathrm{CH}_{2} \mathrm{Cl}_{2}, \mathrm{rt}, 16 \mathrm{~h} ; \mathrm{Et}_{3} \mathrm{~N}, \mathrm{BF}_{3} \cdot \mathrm{Et}_{2} \mathrm{O}, \mathrm{rt}$, 1h; (ii) NIS, $\mathrm{CH}_{2} \mathrm{Cl}_{2}$, rt, 30 min; (iii) morpholine, $\mathrm{CH}_{2} \mathrm{Cl}_{2}$, reflux, $3 \mathrm{~h}$ or morpholine, $\mathrm{Et}_{3} \mathrm{~N}$, reflux, $3 \mathrm{~d}$; (iv) NIS, $\mathrm{CH}_{2} \mathrm{Cl}_{2}, \mathrm{rt}, 30 \mathrm{~min}$; morpholine, reflux, $1 \mathrm{~h}$.

\section{Experimental Part}

General Experimental: All reagents and solvents were purchased from Aldrich Chemicals, Alfa Aesar or Fisher Scientific UK, and used without further purification unless otherwise stated. Thin layer chromatography (TLC) was used to monitor the reactions. Column chromatography was used for purification (unless otherwise stated) using silica gel (Merck silica gel 60, 0.2-0.5 mm, 50-130 mesh). ${ }^{1} \mathrm{H}$ and ${ }^{13} \mathrm{C}\left\{{ }^{1} \mathrm{H}\right\}$ NMR spectra were recorded at room temperature with either a Bruker AV400 or a Bruker AV3400, operating at 400 and $100 \mathrm{MHz}$, respectively. ${ }^{11} \mathrm{~B}$ and ${ }^{19} \mathrm{~F}$ NMR spectra were recorded at room temperature with Bruker AV3400, operating at 128 and $376 \mathrm{MHz}$, respectively. Chemical shifts are quoted in ppm relative to TMS $\left({ }^{1} \mathrm{H}\right.$ and $\left.\left.{ }^{13} \mathrm{C}_{\{}{ }^{1} \mathrm{H}\right\}\right)$. $\mathrm{BF}_{3} \cdot \mathrm{OEt}_{2}$ was used as an external reference for ${ }^{11} \mathrm{~B}$ NMR measurements and $\mathrm{CFCl}_{3}$ as an external reference for ${ }^{19} \mathrm{~F}$ NMR. Elemental microanalyses were performed at the Analytical Services, School of Chemistry, University of Nottingham.

Electrochemical Measurements: Cyclic Voltammetry (CV) experiments were performed using an Autolab PGSTAT20 potentiostat with a three-electrode arrangement in a single-compartment cell under an atmosphere of argon. A glassy carbon working electrode, a Pt wire secondary electrode and a saturated calomel reference electrode were chemically isolated from the test solution by a bridge tube containing electrolyte solution and fitted with a porous vycor frit and were used in the cell. The solutions were $10^{-3} \mathrm{M}$ in test compounds and $0.4 \mathrm{M}$ in $\left[{ }^{n} \mathrm{Bu}_{4} \mathrm{~N}\right]\left[\mathrm{BF}_{4}\right]$ as supporting electrolyte. The redox potentials are quoted versus the ferrocenium-ferrocene couple $\left(\mathrm{Fc}^{+} / \mathrm{Fc}\right)$ which was used as an internal reference [23]. Compensation for internal resistance was not applied. Dichloromethane was dried over molecular sieves under dinitrogen gas, ferrocene (Aldrich) was used as received and $\left[{ }^{n} \mathrm{Bu}_{4} \mathrm{~N}\right]\left[\mathrm{BF}_{4}\right]$ was prepared by a literature method [24].

Photophysical Measurement: Absorption UV-Vis and fluorescence measurements were carried out at the University of Nottingham. Absorption UV-Vis spectra of solutions were measured with a Perkin Elmer Lambda $25 \mathrm{UV}$-Vis spectrometer in $1 \mathrm{~cm}$ length quartz cuvettes. Excitation and emission photoluminescence spectra of solution samples were performed using an Edinburgh Instruments FLS920 Fluorometer. The fluorescence samples were run in standard quartz fluorescence cuvettes, $1=1$ $\times 1 \mathrm{~cm}$. All spectroscopy experiments were performed using spectrophotometric grade solvent and 
solution concentrations never exceeded $\mathrm{A}=0.10$ at the excitation wavelength or any longer wavelength, to minimise inner filter effects.

Synthetic Procedures: Compounds 1 and 2 [9] were synthesised according to literature procedures. 2,6-diiodo-5,7-dimethyl-1,3-bis(methylene)dimorpholine,8-phenyl-4,4-difluoroboradiazaindacene (3). To a solution of $\mathbf{1}(170 \mathrm{mg}, 0.51 \mathrm{mmol})$ in $\mathrm{CH}_{2} \mathrm{Cl}_{2}(25 \mathrm{~mL})$ was added 4 equivalents of $\mathrm{N}$-iodosuccinimide ( $459 \mathrm{mg}, 2.04 \mathrm{mmol}$ ). The resulting mixture was stirred at room temperature in the absence of light for $1 \mathrm{~h}$. Morpholine $\left(2 \mathrm{~cm}^{3}, 2.04 \mathrm{mmol}\right)$ was added and the reaction mixture was heated at reflux for $1 \mathrm{~h}$. The crude product was concentrated under vacuum and purified by silica gel column chromatography (n-hexane/ $\left.\mathrm{CH}_{2} \mathrm{Cl}_{2}, 1: 2\right)$. The deep red-coloured fraction was collected, and the solvent removed under reduced pressure to yield the desired compound as a red solid. Yield $90 \mathrm{mg}(26 \%) .{ }^{1} \mathrm{H} \mathrm{NMR}(400 \mathrm{MHz}$, $\left.\mathrm{CDCl}_{3}\right) \delta 7.57-7.55(\mathrm{~m}, 3 \mathrm{H}), 7.29-7.30(\mathrm{~m}, 2 \mathrm{H}), 3.84(\mathrm{~s}, 4 \mathrm{H}) 3.36-3.76(\mathrm{t}, J=4.6 \mathrm{~Hz}, 8 \mathrm{H}), 2.65(\mathrm{t}, J=4.6 \mathrm{~Hz}$, $8 \mathrm{H}), 1.43(\mathrm{~s}, 6 \mathrm{H}) ;{ }^{13} \mathrm{C}$ NMR $\left(500 \mathrm{MHz}, \mathrm{CDCl}_{3}\right) \delta 155.96,146.46,143.37,134.58,131.20,129.74,127.60$, 67.11, 53.63. 29.72 16.98; ${ }^{11} \mathrm{~B}$ NMR $\left(128 \mathrm{MHz}, \mathrm{CDCl}_{3}\right) \delta 0.6(\mathrm{t}, J=33.1 \mathrm{~Hz}) ;{ }^{19} \mathrm{~F}$ NMR: $\left(376 \mathrm{MHz}, \mathrm{CDCl}_{3}\right)$ $\delta-134.1(\mathrm{q}, J=33.1 \mathrm{~Hz})$. (MALDI-TOF, DCTB/MeCN): $\mathrm{m} / \mathrm{z}$ calculated 746.06, observed 746.1([M] ${ }^{+}$,

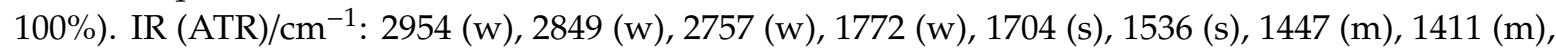
$1346(\mathrm{~s}), 1175(\mathrm{~s}), 1149(\mathrm{~m}), 1102(\mathrm{~s}), 1004(\mathrm{~m}), 978(\mathrm{~m}), 913(\mathrm{~m}), 858(\mathrm{~m}), 724(\mathrm{~s}), 630(\mathrm{w}), 537(\mathrm{w}), 485$ (w). Elemental Analysis: Calcd for $\mathrm{C}_{32} \mathrm{H}_{43} \mathrm{BF}_{2} \mathrm{I}_{2} \mathrm{~N}_{4} \mathrm{O}_{2}: \mathrm{C}, 46.97 ; \mathrm{H}, 5.30 ; \mathrm{N}, 6.85$. Found: $\mathrm{C}, 46.45 ; \mathrm{H}$, $5.11 ; \mathrm{N}, 6.35$.

Single Crystal X-ray Diffraction Studies: Single crystal diffraction data were collected for $\mathbf{2}$ and $\mathbf{3}$, at 120(2) K on a Rigaku Oxford Diffraction SuperNova, Atlas GV1000 diffractometer using mirror monochromated $\mathrm{Cu} \mathrm{K} \mathrm{K}_{\alpha}$ radiation. Using Olex2 [25] the structure was solved with the ShelXT [26] structure solution program using intrinsic phasing and refined with the ShelXL [27] refinement package using least squares minimisation. All non-hydrogen atoms were refined with anisotropic displacement parameters. Hydrogen atoms were placed in calculated positions and thereafter refined using a riding model with $\operatorname{Uiso}(\mathrm{H})=1.2 U_{\mathrm{eq}}(\mathrm{C})$ or $\operatorname{Uiso}(\mathrm{H})=1.5 U_{\mathrm{eq}}(\mathrm{C})$ for methyl $\mathrm{H}$ atoms. Visualizing interactions in molecular crystals using Hirshfeld surface tools and 2D fingerprint plot (FPs) were analysed using Crystal Explorer (Version 3.1, and 17.1) [28,29].

Crystal data for 2: $\mathrm{C}_{19} \mathrm{H}_{17} \mathrm{BF}_{2} \mathrm{I}_{2} \mathrm{~N}_{2}$ : space group $P 22_{1} / n$ (no. 14), $a=11.4551(3) \AA, b=12.9407(4) \AA$, $c=13.2532(4) \AA, \beta=90.788(2)^{\circ}, \mathrm{V}=1964.43(10), \mathrm{Z}=4, \mathrm{D}_{\text {calc }}=1.947 \mathrm{~g} \mathrm{~cm}^{-3}, \mu=25.351 \mathrm{~mm}^{-1}, \mathrm{~F}(000)=$ 1096.0. A total of 7967 reflections were collected, of which 3866 were unique, with $R_{\text {int }}=0.0275$. Final $R_{1}\left(\mathrm{w} R_{2}\right)=0.0273(0.0683)$ with $\mathrm{GOF}=1.074$.

Crystal data for 3: $\mathrm{C}_{27} \mathrm{H}_{31} \mathrm{BF}_{2} \mathrm{I}_{2} \mathrm{~N}_{4} \mathrm{O}$. Orthorhombic, space group $P 2_{1} 2_{1} 2_{1}$ (no. 19) $a=6.5790(10)$ $\AA, b=18.7712(4) \AA, c=23.3004(4), V=2877.50(9) \AA^{3}, Z=4, D_{\text {calc }}=1.722 \mathrm{~g} \mathrm{~cm}^{-3}, \mu=17.541 \mathrm{~mm}^{-1}$, $\mathrm{F}(000)=1464.0$. A total of 27,321 reflections were collected, of which 5705 were unique, with $R_{\text {int }}=$ 0.0921 . Final $R_{1}\left(\mathrm{w} R_{2}\right)=0.0348(0.0710)$ with $\mathrm{GOF}=1.003$. Flack parameter $=-0.022(7)$.

\section{Results and Discussion}

2 was synthesised by direct electrophilic halogenation of $\mathbf{1}$ [9] using $\mathrm{N}$-iodosuccinimide (NIS) $[9,30]$. Interestingly, the direct reaction of the $\beta$-halogenated BODIPY (2) with morpholine did not result in nucleophilic substitution of either halogenated $\beta$-positions or the $\alpha$-methyl groups. However, reaction of 1 with NIS in $\mathrm{CH}_{2} \mathrm{Cl}_{2}$ for 30 minutes followed by reflux with morpholine for a further hour gave 3 , in $26 \%$ yield, which combines both iodo and amino substituents. The intermediate species with iodinated $\alpha$-methyl groups could not be isolated [11]. Instead, the direct reaction of $\mathbf{1}$ with morpholine, in the presence of NIS, resulted in amine substitution of this position.

The packing motif observed for BODIPY compounds can significantly affect their absorption and emission behaviour [30,31]. Although in this case neither 2 nor 3 exhibited solid-state emission $\left(\lambda_{\text {excitation }}=365 \mathrm{~nm}\right)$, we investigated the packing arrangements exhibited by 2 and 3 . Single crystals of 2 and 3 were grown by vapour diffusion of diethyl ether into $n$-hexane solutions of the target compound (Figure 1). Structural determination by single-crystal X-ray diffraction revealed the BODIPY species to crystallise in the monoclinic space group $P 2_{1} / n$ for 2 and in the orthorhombic space group $P 2_{1} 2_{1} 2_{1}$ for 
3. The X-ray crystal structures confirmed the chemical composition of both compounds as determined by NMR spectroscopy.

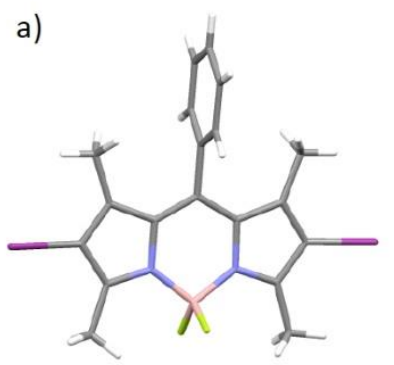

b)

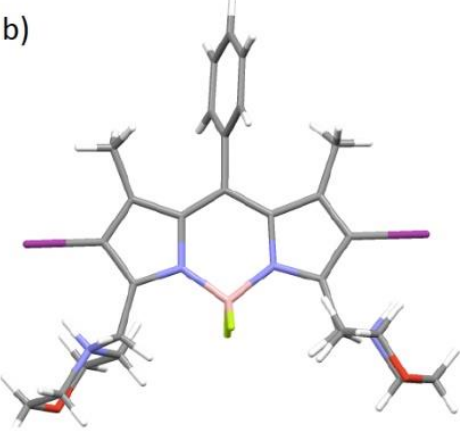

c)
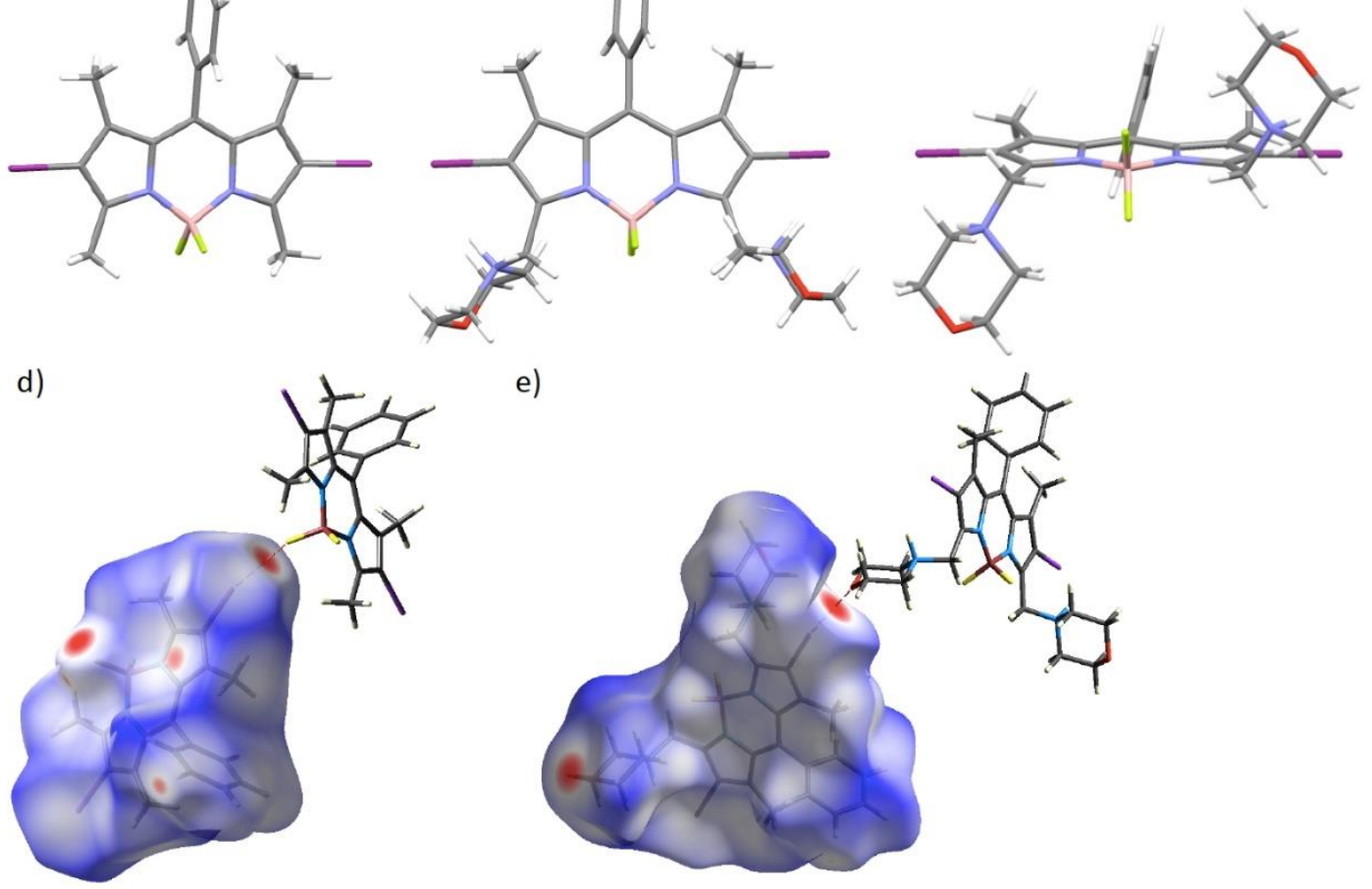

e)

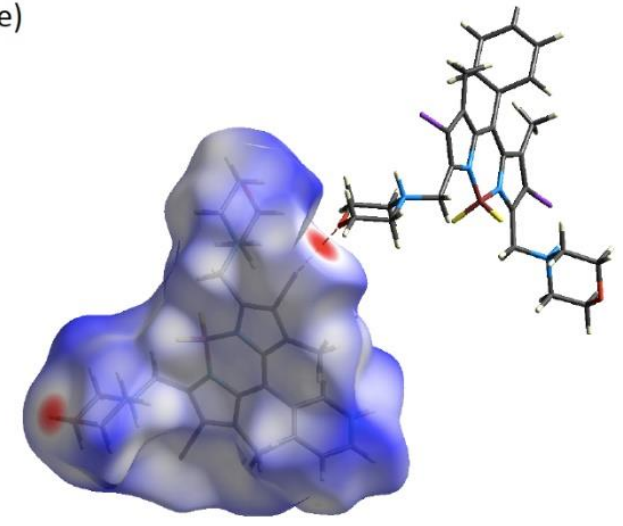

Figure 1. Crystal structure of (a) 2 and (b,c) 3 , in the latter case illustrating the relative orientation of the morpholino substituents in relation to the dipyrrin core; (d) Hirshfeld surface representation of (d) $\mathrm{C}-\mathrm{I} \cdots \mathrm{F}$ interaction in $\mathbf{2}$ and (e) $\mathrm{C}-\mathrm{I} \cdots \mathrm{O}$ interaction in $\mathbf{3}$. C = grey, $\mathrm{N}=$ blue, $\mathrm{B}=$ pink, $\mathrm{F}=$ green, $\mathrm{I}=$ purple, $\mathrm{O}=$ red, $\mathrm{H}=$ white.

In comparison to previously reported boron-dipyrromethene compounds, the X-ray crystal structures of $\mathbf{2}$ and 3 revealed the expected planarity of the BODIPY core that extended through the 2,6-diiodo groups (Figure 1a-c), with the meso phenyl ring approximately orthogonal to the indacene plane (angle between least-squares planes of the meso phenyl ring and indacene group: $2=88.2^{\circ} ; 3=$ $75.9^{\circ}$ ). In 3 , the morpholino appendages are found to be positioned above and below the indacene plane as a result of the orientation of the methylene group linking the two groups $\left[\mathrm{C}_{\alpha p y r r o l e}-\mathrm{C}_{\alpha c a r b o n}-\mathrm{N}_{\text {Morph }}\right.$ $=109^{\circ}$ ] (Figure 1c).

Three polymorphs of 2,6-diiodo-1,3,5,7-tetramethyl-8-phenyl-4,4-difluoroboradiazaindacene, named $\mathbf{2}$ herein, have been reported [32-37]. Inspection of the packing of $\mathbf{2}$ reveals that this structure is polymorph I [32-35]. In this polymorph, a zig-zag linear pattern is observed due to the formation of $\mathrm{C}-\mathrm{I} \cdots \mathrm{F}$ interactions between an iodine-atom on one BODIPY and the fluorine atoms from the neighbouring BODIPY (Figure 1d). Bond lengths and angles are consistent with type I [38] halogen interactions [39-41] [for 2: $\mathrm{I} \cdots \mathrm{F}=3.1165(19) \AA$; C-I $\cdots \mathrm{F}=163.89(11)^{\circ}, \mathrm{B}-\mathrm{F} \cdots \mathrm{I}=152.64(19)^{\circ}$ ] (see Supplementary Materials for view of zig-zag chain). In order to confirm the occurrence of these C-I $\cdots \mathrm{F}$ interactions in 2, Hirshfeld surface analysis was undertaken.

Inspection of the Hirshfeld surfaces of 2 (Figure 1d) indicates that the most significant intermolecular interactions involve the C-I $\cdots \mathrm{F}$ interaction discussed above. The iodine atom not involved in this $\mathrm{C}-\mathrm{I} \cdots \mathrm{F}$ interaction does not engage in halogen bonding but rather acts as an acceptor in a short $(\mathrm{C}-\mathrm{H} \cdots \mathrm{I})$ contact involving a methyl group of an $\alpha$-carbon from the neighbouring BODIPY. Polymorph II [36] exhibits a distinct packing arrangement to polymorph I. Although a zig-zag linear pattern is also observed in this polymorph, the packing arises due to intermolecular I $\cdots$ I interactions 
$\left[\mathrm{I} \cdots \mathrm{I}=3.78(8) \AA ; \mathrm{C}-\mathrm{I} \cdots \mathrm{I}=114.30(2)^{\circ}, 163.30(2)^{\circ} ; 112,50(2)^{\circ}, 160.20(3)^{\circ}\right]($ see Supplementary Materials for view of zig-zag chain). Polymorph III [37], like polymorph I, adopts C-I $\cdots$ F interactions between adjacent molecules and forms a zig-zag arrangement but of a more compact nature with a less-linear $\mathrm{C}-\mathrm{I} \cdots \mathrm{F}$ angle than that observed in polymorph I $\left[\mathrm{I} \cdots \mathrm{F}=3.24(8) \AA\right.$; $; \mathrm{C}-\mathrm{I} \cdots \mathrm{F}=108.18(6)^{\circ}, \mathrm{B}-\mathrm{F} \cdots \mathrm{I}=$ $\left.173.25(3)^{\circ}\right]$ (see Supplementary Materials for view of polymorph III).

Hirshfeld surface analysis was also performed for 3 revealing the presence of $\mathrm{C}-\mathrm{I} \cdots \mathrm{O}$ interactions (Figure 1e) [42-44]. The unusual C-I $\cdots$ O halogen interaction, [C-I $\cdots \mathrm{O}=2.972(6) \AA, \mathrm{C}-\mathrm{I} \cdots \mathrm{O}=166.70(2)^{\circ}$, $\mathrm{C}-\mathrm{O} \cdots \mathrm{I}=105.00(5)^{\circ} \mathrm{]}$ exhibits a short $\mathrm{I} \cdots \mathrm{O}$ distance, over $20 \%$ shorter than the sum of mean van der Waals radii of the two atoms (3.49 $\AA$ ) [44], suggesting a strong interaction. In contrast to 2, no close $\mathrm{C}-\mathrm{I} \cdots \mathrm{F}$ interactions are observed in 3, possibly due to presence of the morpholino moieties, resulting in a more favourable $\mathrm{I} \cdots \mathrm{O}$ interaction being adopted. The packing diagram of $\mathbf{3}$ confirms the presence of halogen bonds leading to the formation of a framework structure (Figure 2). Each molecule of 3 forms $\mathrm{C}-\mathrm{I} \cdots \mathrm{O}$ halogen bonds to four nearest neighbour molecules, ultimately forming a three-dimensional halogen-bonded framework with pseudo-diamondoid topology. No I ... I or F . . . F interactions are observed in the structure of 3 . It is notable that the presence of additional halogen bond acceptors in 3 , the morpholino oxygen atoms, results in a significantly different crystalline framework structure in comparison to the zig-zag chains observed in all polymorphs of 2 .

a)

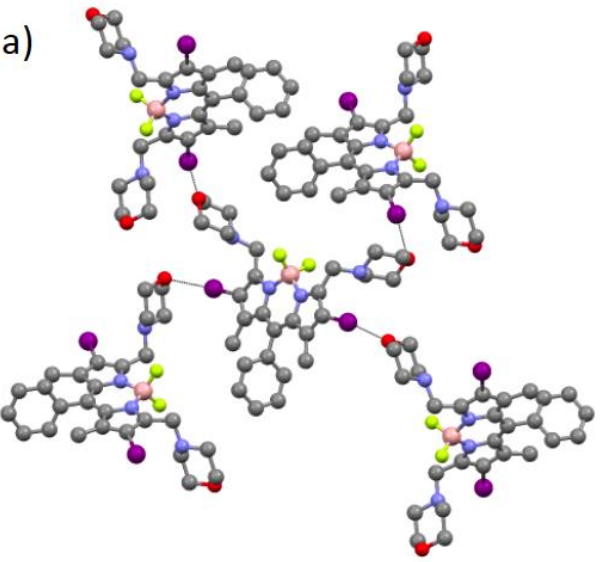

c)

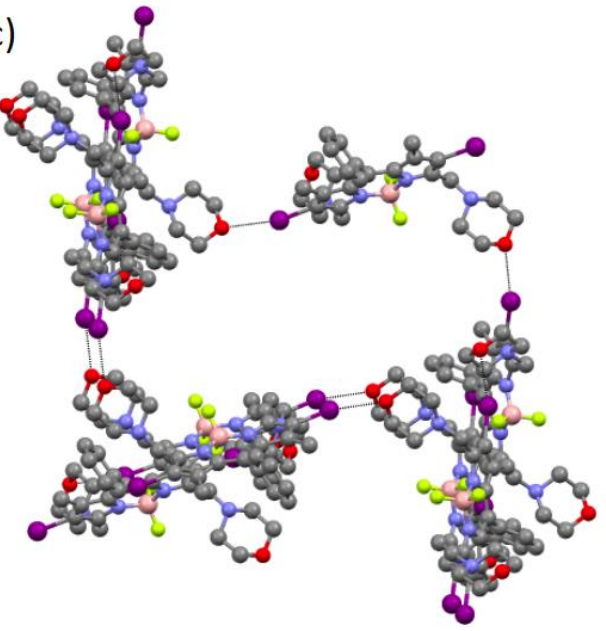

b)

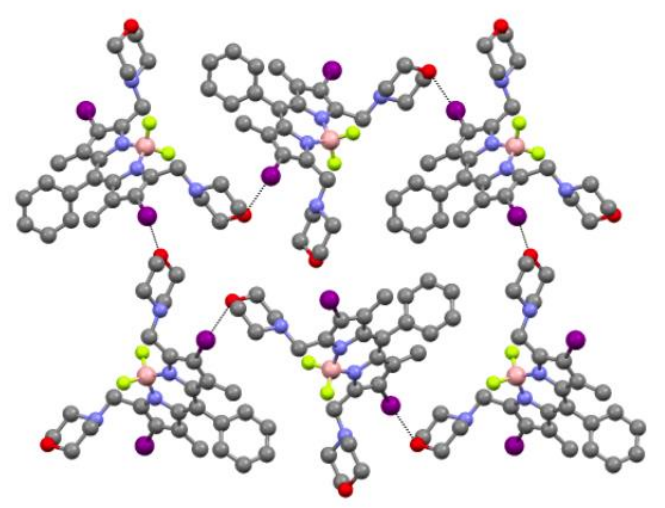

d)

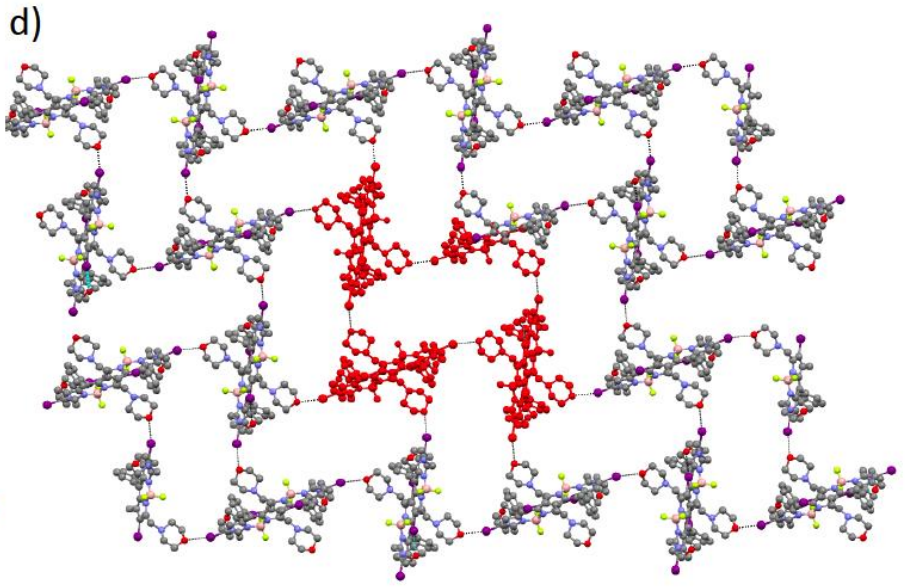

Figure 2. Views of the crystal structure of 3 illustrating the overall halogen bonded framework and illustrating (a) each molecule connected to four nearest neighbours, (b) the formation of a six-membered ring and (c) an adamantane-like unit that is a component of $(\mathbf{d})$ the overall pseudo-diamondoid network. In (d) the adamantane-like unit, shown in (c), is highlighted in red. $\mathrm{C}=$ grey, $\mathrm{N}=$ blue, $\mathrm{B}=$ pink, $\mathrm{F}=$ green, $\mathrm{I}=$ purple, $\mathrm{O}=$ red, $\mathrm{H}=$ white. Black dashed lines represent $\mathrm{C}-\mathrm{I} \cdots \mathrm{O}$ halogen bonds. 
The optical properties of 2 and 3 give UV-visible spectral profiles characteristic of BODIPY compounds (Table 1 ) with bands corresponding to the $\left(S_{0} \rightarrow S_{1}, \pi-\pi^{*}\right)$ transition of the dipyrrin ligands. The band maxima of 2 and 3 in $\mathrm{CH}_{2} \mathrm{Cl}_{2}$ were observed at 534 and $539 \mathrm{~nm}$, respectively, showing that iodination at the 2- and 6-positions of the dipyrrin results in bathochromic shifts of approximately $30 \mathrm{~nm}$ in the absorption maximum of 2 in comparison with $\mathbf{1}$ and a $19 \mathrm{~nm}$ bathochromic shift in comparison to the previously reported mono-iodinated derivatives [32]. The morpholino substituted species, 3, displays intense absorptions of approximately three times the intensity of those observed for 2 , which also show a further small bathochromic shift. This results in substantial colour changes for solutions of the three compounds (Figure 3). It is also noticeable that for $\mathbf{3}$, fluorescence is essentially quenched with very low quantum yield, $\Phi_{\mathrm{F}}=0.0006$ in $\mathrm{CH}_{2} \mathrm{Cl}_{2}$ in comparison to values of 0.63 [33] or 0.05 [33] for 1 and 2, respectively. This quenching can be attributed to the presence of the tertiary amine of the morpholino-substituent.

Table 1. Summary of cyclic voltammetry data, absorption wavelengths $\left(\lambda_{\mathrm{abs}}\right)$ and extinction coefficients $(\varepsilon)$ for neutral and reduced species and emission data for compounds 1-3. a

\begin{tabular}{|c|c|c|c|c|c|}
\hline \multirow{2}{*}{ Compound } & \multirow{2}{*}{$\mathrm{E}_{1 / 2} / \mathrm{V}(\Delta \mathrm{E})$} & \multicolumn{2}{|c|}{$\lambda_{\mathrm{abs}} / \mathrm{nm}\left(\varepsilon \times 10^{-4} / \mathrm{dm}^{3} \mathrm{~mol}^{-1} \mathrm{~cm}^{-1}\right)^{b}$} & \multirow{2}{*}{$\lambda_{\mathrm{em}} / \mathrm{nm}^{\mathrm{e}}$} & \multirow{2}{*}{$\Phi_{\text {Yield }}^{\Phi^{\text {Quantum }}}$} \\
\hline & & Neutral Species & Radical Anion & & \\
\hline 1 & $-1.60(0.08)^{c}$ & $501(1.1)$ & $\begin{array}{c}287(0.2), 340(0.2) \\
473(0.1), 528(0.1) \\
571(0.1)\end{array}$ & $511^{\mathrm{f}}$ & $0.63^{f}$ \\
\hline 2 & $-1.37(0.08)^{\mathrm{c}}$ & $384(0.7), 534(6.4)$ & $\begin{array}{c}304(1.0), 343(1.1) \\
493(0.2), 528(0.4) \\
569(1.0)\end{array}$ & $550^{\mathrm{f}}$ & $0.05^{\mathrm{f}}$ \\
\hline 3 & $-1.30(0.07)^{d}$ & $389(2.2), 538(20.2)$ & $\begin{array}{l}303(2.3), 357(2.0) \\
529(0.6), 568(1.7)\end{array}$ & 556 & 0.0006 \\
\hline
\end{tabular}

${ }^{\mathrm{a}}$ In $\mathrm{CH}_{2} \mathrm{Cl}_{2}$ containing $\left[{ }^{n} \mathrm{Bu}_{4} \mathrm{~N}\right]\left[\mathrm{BF}_{4}\right](0.4 \mathrm{M}) ;{ }^{\mathrm{b}}$ at $243 \mathrm{~K} ;{ }^{\mathrm{c}}$ oxidation process at $\mathrm{E}_{1 / 2}+0.77 \mathrm{~V} ;{ }^{\mathrm{d}}$ oxidation process at $\mathrm{E}_{\mathrm{p}}{ }^{\mathrm{a}}+0.83 \mathrm{~V} ;{ }^{\mathrm{e}}$ recorded in $\mathrm{CH}_{2} \mathrm{Cl}_{2} ;{ }^{\mathrm{f}}$ from reference [32].

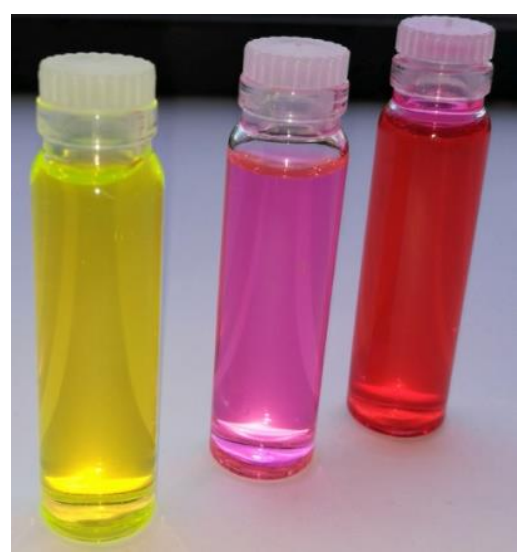

Figure 3. Photograph showing the different in colour of $\mathrm{CH}_{2} \mathrm{Cl}_{2}$ solutions of (left to right) 1, 2, and 3.

The redox behaviour of 1,2 and 3 in $\mathrm{CH}_{2} \mathrm{Cl}_{2}$ solution was investigated by cyclic voltammetry and UV-Vis spectroelectrochemistry (Table 1). In line with previous observations all oxidations and reductions are based on the dipyrrin component of the molecule [45]. An electrochemically reversible one electron reduction process is observed for each compound (Figure 4) with the presence of the iodo substituents shifting this redox process to more positive values by more than $0.2 \mathrm{~V}$, i.e., making the compound easier to reduce. The introduction of the morpholino substituents in 3 shifts the potential to a more positive potential in comparison to 2 suggesting a further decrease of electron density in the BODIPY manifold. In all cases oxidation processes were observed at positive potentials (Figure 4 and Table 1). For $\mathbf{1}$ and $\mathbf{2}$, the oxidation appears reversible at faster scan rates, but as the scan rate 
is decreased, the magnitude of the current in the second half cycle of the CV is reduced suggesting instability of the oxidised species in the diffusion layer. Inclusion of morpholine in $\mathbf{3}$ appears to change the nature of the oxidation process compared to $\mathbf{1}$ and $\mathbf{2}$, with no return wave observed in the second half-cycle of the CV experiment. As would be expected, the presence of electron-withdrawing iodo substituents in $\mathbf{2}$ and $\mathbf{3}$ makes the BODIPY framework less electron rich and therefore the corresponding oxidation process more difficult compared to that in $\mathbf{1}$. The oxidation processes were not studied further.

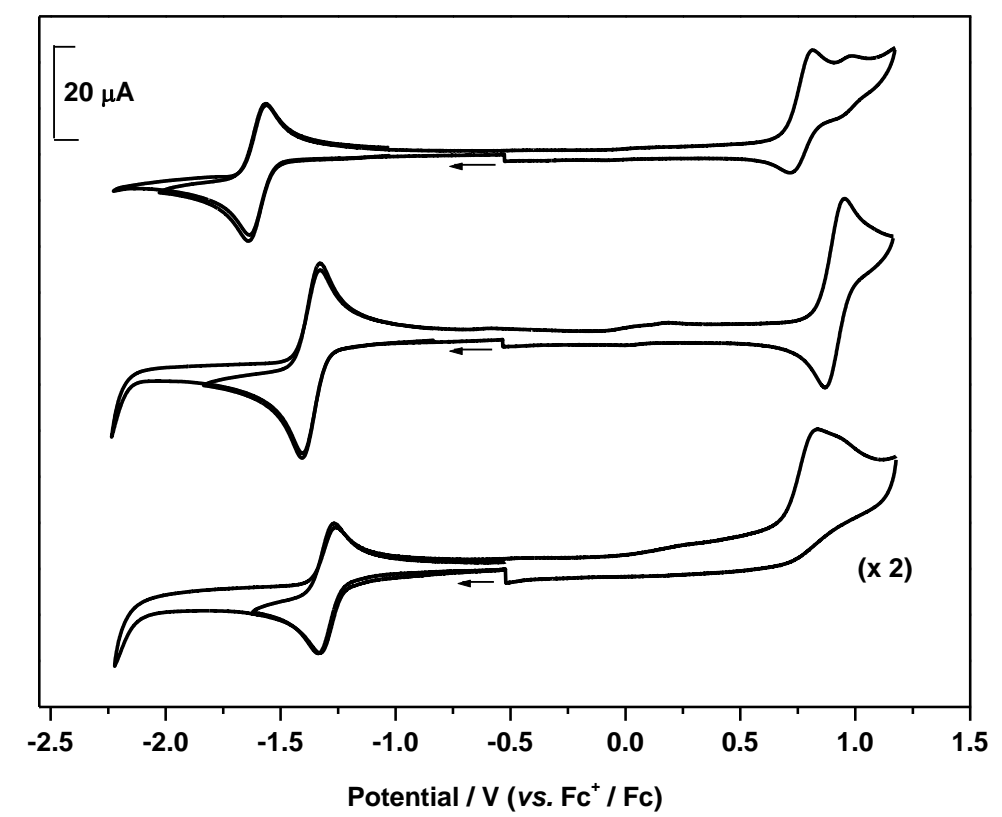

Figure 4. Cyclic voltammograms of $\mathbf{1}$ (upper traces), $\mathbf{2}$ (middle traces) and $\mathbf{3}$ (lower traces) at RT in $\mathrm{CH}_{2} \mathrm{Cl}_{2}$ with $\left[{ }^{n} \mathrm{Bu}_{4} \mathrm{~N}\right]\left[\mathrm{BF}_{4}\right](0.4 \mathrm{M})$ as supporting electrolyte.

In situ spectroelectrochemical methods were employed to probe the UV-Vis spectroscopic changes that accompany the one-electron reduction processes of 2 and 3 (Table 1; Figures 5 and 6; see Supplementary Materials for further figures). The in situ one-electron reduction of each compound was followed by UV-vis spectroelectrochemistry at an optically transparent electrode. Generation of the one-electron reduced radical anion shows depletion of the major bands for the neutral species (ca. $534 \mathrm{~nm}$ for 2, and $538 \mathrm{~nm}$ for 3 ) and the corresponding development of a series of bands in the range $510-570 \mathrm{~nm}$ for 2 and 3, all with significantly smaller absorption coefficients. In the range $290-450 \mathrm{~nm}$, reduction leads to the development of new bands at ca. 300 and $350 \mathrm{~nm}$ for 2 and ca. 303 and $353 \mathrm{~nm}$ for 3. Applying a potential sufficient to reverse the reduction process did not regenerate the spectral profile of $\mathbf{2}$ or $\mathbf{3}$ fully, as would be seen if the process was chemically reversible. This is indicative of a chemical instability of the generated radical anion resulting in decomposition to produce an unknown species. These results are largely consistent with unsubstituted BODIPY species [45] despite the substitution of the dipyrrin core and shift of redox potentials to more positive potentials. 


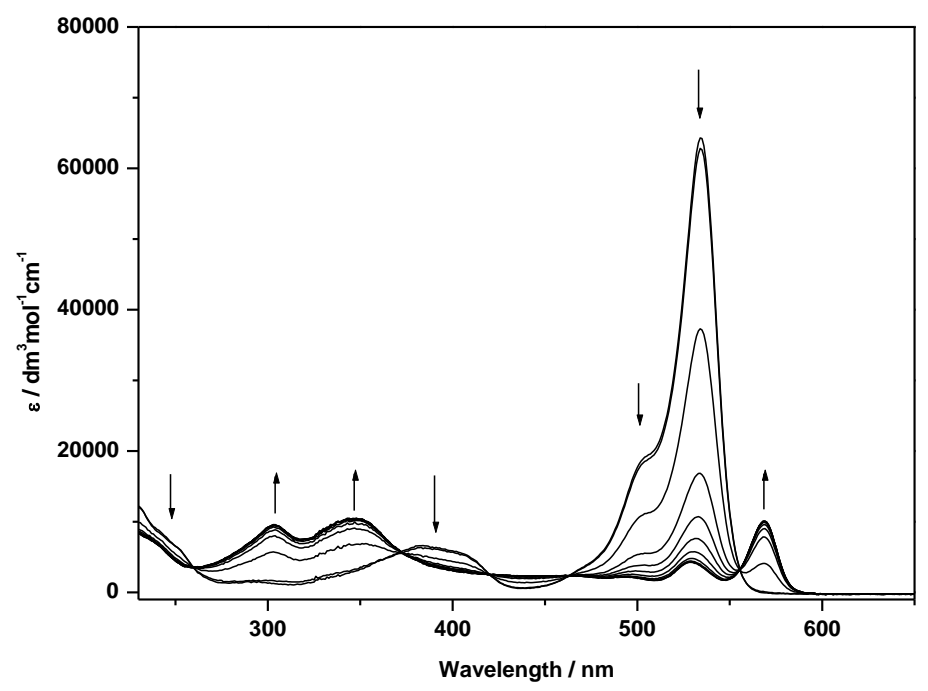

Figure 5. UV-vis spectroelectrochemsitry of 2 in $\mathrm{CH}_{2} \mathrm{Cl}_{2}$ with $\left[{ }^{n} \mathrm{Bu}_{4} \mathrm{~N}\right]\left[\mathrm{BF}_{4}\right]$ as electrolyte at $243 \mathrm{~K}$. Arrows indicate progress of reduction.

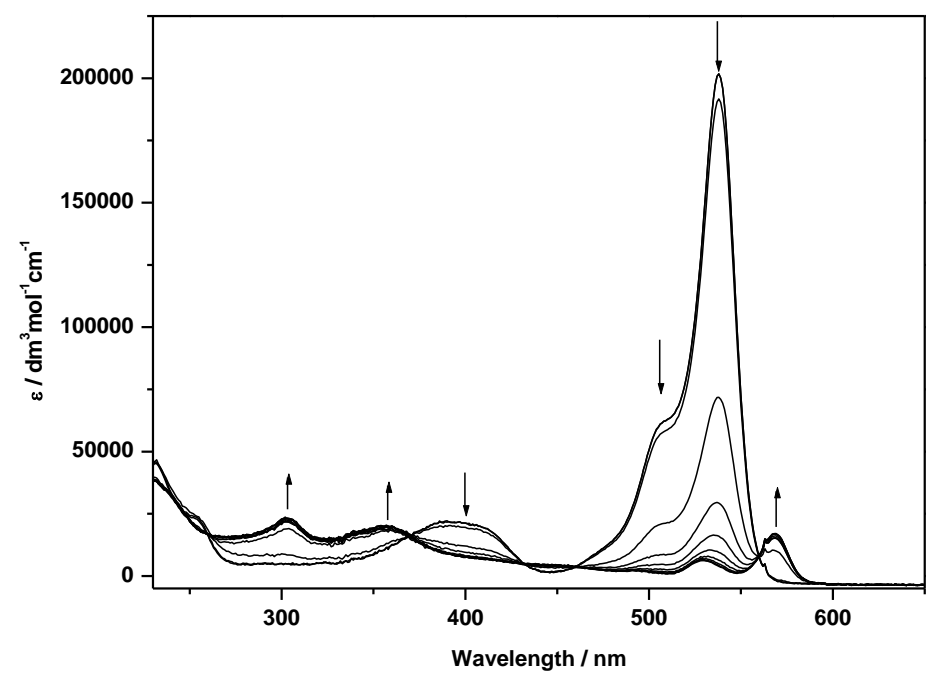

Figure 6. UV-vis spectroelectrochemsitry of 3 in $\mathrm{CH}_{2} \mathrm{Cl}_{2}$ with $\left[{ }^{n} \mathrm{Bu}_{4} \mathrm{~N}\right]\left[\mathrm{BF}_{4}\right]$ as electrolyte at $243 \mathrm{~K}$. Arrows indicate progress of reduction.

\section{Conclusions}

In summary, we have demonstrated that it is possible to functionalize BODIPY with non-conjugated tertiary amine substitution in combination with iodo-substitution on the dipyrrin core giving rise to highly coloured dye molecules with intense absorptions. The shift in absorption wavelength is paralleled by a shift in reduction potentials to more positive values upon introduction of iodo and tertiary amine groups to the BODIPY scaffold. The introduction of iodo-substituents also leads to the adoption of halogen bonding interactions in the solid-state structures of $\mathbf{2}$ and $\mathbf{3}$. Whereas $\mathbf{2}$

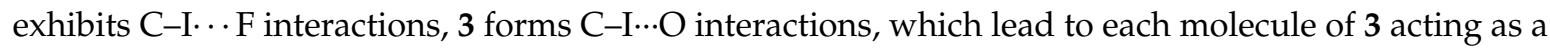
fourfold-connected tecton and thus creating a three-dimensional framework of pseudo-diamondoid topology. In summary our study demonstrates that the introduction of different chemical functionalities can be used in an additive fashion to shift reduction potentials of the BODIPY core and can be used to create frameworks through the adoption of halogen bonding interactions.

Supplementary Materials: The following are available online at http://www.mdpi.com/2073-4352/10/1/36/s1. Additional Figures. CCDC 1963595 and 1963596 contain the supplementary crystallographic data for this 
paper. These data can be obtained free of charge from the Cambridge Crystallographic Data Centre via www.ccdc.cam.ac.uk/data_request/cif.

Author Contributions: Conceptualization, N.R.C. and D.L.K.; Methodology, H.H., E.S.D. and N.R.C.; Validation, H.H., E.S.D. and W.L.; Investigation, H.H. and E.S.D.; supervision, N.R.C. and D.L.K. All authors have read and agreed to the published version of the manuscript.

Funding: This research was funded by the UK Engineering and Physical Sciences Research Council (EP/S002995/1) and support for H.H. from University of Jeddah (Jeddah, Saudi Arabia).

Acknowledgments: We gratefully acknowledge the support of University of Jeddah (Jeddah, Saudi Arabia) for providing a scholarship for HH. NRC acknowledges financial support from the UK Engineering and Physical Sciences Research Council (EP/S002995/1).

Conflicts of Interest: There are no conflicts to declare.

\section{References}

1. Boens, N.; Leen, V.; Dehaen, W. Fluorescent indicators based on BODIPY. Chem. Soc. Rev. 2012, 41, 1130-1172. [CrossRef]

2. Ulrich, G.; Ziessel, R.; Harriman, A. The Chemistry of Fluorescent Bodipy Dyes: Versatility Unsurpassed. Angew. Chem. Int. Ed. 2008, 47, 1184-1201. [CrossRef]

3. Ziessel, R.; Ulrich, G.; Harriman, A. The chemistry of Bodipy: A new El Dorado for fluorescence tools. New J. Chem. 2007, 31, 496-501. [CrossRef]

4. Wang, L.; Wang, J.-W.; Cui, A.-J.; Cai, X.-X.; Wan, Y.; Chen, Q.; He, M.-Y.; Zhang, W. Regioselective 2,6-dihalogenation of BODIPYs in 1,1,1,3,3,3-hexafluoro-2-propanol and preparation of novel meso-alkyl polymeric BODIPY dyes. RSC Adv. 2013, 3, 9219-9222. [CrossRef]

5. Wagner, R.W.; Lindsey, J.S. Boron-dipyrromethene dyes for incorporation in synthetic multi-pigment light-harvesting arrays. Pure Appl. Chem. 1996, 68, 1373-1380. [CrossRef]

6. El-Khouly, M.E.; Fukuzumi, S.; D'Souza, F. Photosynthetic Antenna-Reaction Center Mimicry by Using Boron Dipyrromethene Sensitizers. ChemPhysChem 2014, 15, 30-47. [CrossRef]

7. Kumaresan, D.; Thummel, R.P.; Bura, T.; Ulrich, G.; Ziessel, R. Color Tuning in New Metal-Free Organic Sensitizers (Bodipys) for Dye-Sensitized Solar Cells. Chem. Eur. J. 2009, 15, 6335-6339. [CrossRef]

8. Coskun, A.; Deniz, E.; Akkaya, E.U. Effective PET and ICT Switching of Boradiazaindacene Emission: A Unimolecular, Emission-Mode, Molecular Half-Subtractor with Reconfigurable Logic Gates. Org. Lett. 2005, 7, 5187-5189. [CrossRef]

9. Zhou, Q.; Zhou, M.; Wei, Y.; Zhou, X.; Liu, S.; Zhang, S.; Zhang, B. Solvent effects on the triplet-triplet annihilation upconversion of diiodo-Bodipy and perylene. Phys. Chem. Chem. Phys. 2017, 19, 1516-1525. [CrossRef]

10. Zhang, C.; Zhao, J.; Wu, S.; Wang, Z.; Wu, W.; Ma, J.; Guo, S.; Huang, L. Intramolecular RET Enhanced Visible Light-Absorbing Bodipy Organic Triplet Photosensitizers and Application in Photooxidation and Triplet-Triplet Annihilation Upconversion. J. Am. Chem. Soc. 2013, 135, 10566-10578. [CrossRef]

11. Ulrich, G.; Ziessel, R.; Haefele, A. A General Synthetic Route to 3,5-Substituted Boron Dipyrromethenes: Applications and Properties. J. Org. Chem. 2012, 77, 4298-4311. [CrossRef]

12. Yogo, T.; Urano, Y.; Ishitsuka, Y.; Maniwa, F.; Nagano, T. Highly Efficient and Photostable Photosensitizer Based on BODIPY Chromophore. J. Am. Chem. Soc. 2005, 127, 12162-12163. [CrossRef]

13. Ziessel, R.; Bonardi, L.; Retailleau, P.; Ulrich, G. Isocyanate-, Isothiocyanate-, Urea-, and Thiourea-Substituted Boron Dipyrromethene Dyes as Fluorescent Probes. J. Org. Chem. 2006, 71, 3093-3102. [CrossRef]

14. Moon, S.Y.; Cha, N.R.; Kim, Y.H.; Chang, S.K. New $\mathrm{Hg}^{2+}$-selective chromo- and fluoroionophore based upon 8-hydroxyquinoline. J. Org. Chem. 2004, 69, 181-183. [CrossRef]

15. Li, G.; Otsuka, Y.; Matsumiya, T.; Suzuki, T.; Li, J.; Takahashi, M.; Yamada, K. A Straightforward Substitution Strategy to Tune BODIPY Dyes Spanning the Near-Infrared Region via Suzuki-Miyaura Cross-Coupling. Materials 2018, 11, 1297. [CrossRef]

16. Li, L.; Nguyen, B.; Burgess, K. Functionalization of the 4,4-difluoro-4-bora-3a,4a-diaza-s-indacene (BODIPY) core. Bioorg. Med. Chem. Lett. 2008, 18, 3112-3116. [CrossRef]

17. Rohand, T.; Baruah, M.; Qin, W.; Boens, N.; Dehaen, W. Functionalisation of fluorescent BODIPY dyes by nucleophilic substitution. Chem. Commun. 2006, 266-268. [CrossRef] 
18. Leen, V.; Braeken, E.; Luckermans, K.; Jackers, C.; Van der Auweraer, M.; Boens, N.; Dehaen, W. 2- and 3-Monohalogenated BODIPY Dyes and Their Functionalized Analogues: Synthesis and Spectroscopy. Eur. J. Org. Chem. 2011, 4386-4396. [CrossRef]

19. Lakshmi, V.; Rajeswara Rao, M.; Ravikanth, M. Halogenated boron-dipyrromethenes: Synthesis, properties and applications. Org. Biomol. Chem. 2015, 13, 2501-2517. [CrossRef]

20. Rohand, T.; Qin, W.; Boens, N.; Dehaen, W. Palladium-Catalyzed Coupling Reactions for the Functionalization of BODIPY Dyes with Fluorescence Spanning the Visible Spectrum. Eur. J. Org. Chem. 2006, 4658-4663. [CrossRef]

21. Leen, V.; Braeken, E.; Luckermans, K.; Jackers, C.; Van der Auweraer, M.; Boens, N.; Dehaen, W. A versatile, modular synthesis of monofunctionalized BODIPY dyes. Chem. Commun. 2009, 4515-4517. [CrossRef]

22. Zhao, N.; Xuan, S.; Fronczek, F.R.; Smith, K.M.; Vicente, M.G.H. Stepwise Polychlorination of 8-Chloro-BODIPY and Regioselective Functionalization of 2,3,5,6,8-Pentachloro-BODIPY. J. Org. Chem. 2015, 80, 8377-8383. [CrossRef] [PubMed]

23. Gagne, R.R.; Koval, C.A.; Lisensky, G.C. Ferrocene as an internal standard for electrochemical measurements. Inorg. Chem. 1980, 19, 2854-2855. [CrossRef]

24. Kubas, G.J.; Monzyk, B.; Crumblis, A.L. Tetrakis(Acetonitrile)Copper(I) Hexafluorophosphate. Inorg. Synth. 2007, 68. [CrossRef]

25. Dolomanov, O.V.; Bourhis, L.J.; Gildea, R.J.; Howard, J.A.K.; Puschmann, H. OLEX2: A complete structure solution, refinement and analysis program. J. Appl. Cryst. 2009, 42, 339-341. [CrossRef]

26. Sheldrick, G.M. SHELXT-Integrated space-group and crystal-structure determination. Acta Crystallogr. Sect. A: Found. Adv. 2015, A71, 3-8. [CrossRef]

27. Sheldrick, G.M. Crystal structure refinement with SHELXL. Acta Cryst. 2008, A64, 112-122. [CrossRef]

28. Wolff, S.K.; Grimwood, D.J.; McKinnon, J.J.; Turner, M.J.; Jayatilaka, M.A.S.D. CrystalExplorer (Version 3.1); University of Western Australia: Perth, Australia, 2012.

29. Wolff, S.K.; Grimwood, D.J.; McKinnon, J.J.; Turner, M.J.; Jayatilaka, M.A.S.D. CrystalExplorer (Version 17.5); University of Western Australia: Perth, Australia, 2017.

30. Fu, G.-L.; Pan, H.; Zhao, Y.-H.; Zhao, C.-H. Solid-state emissive triarylborane-based BODIPY dyes: Photophysical properties and fluorescent sensing for fluoride and cyanide ions. Org. Biomol. Chem. 2011, 9, 8141-8146. [CrossRef]

31. Hassanain, H.; Davies, E.S.; Lewis, W.; Kays, D.L.; Champness, N.R. Structural characterization and optical properties of two copper(I)-iodide BODIPY coordination polymers. CrystEngComm 2019, 21, 4551-4556. [CrossRef]

32. Gorbe, M.; Costero, A.M.; Sancenón, F.; Martínez-Máñez, R.; Ballesteros-Cillero, R.; Ochando, L.E.; Chulvi, K.; Gotor, R.; Gil, S. Halogen-containing BODIPY derivatives for photodynamic therapy. Dye. Pigment. 2019, 160, 198-207. [CrossRef]

33. Gibbs, J.H.; Robins, L.T.; Zhou, Z.; Bobadova-Parvanova, P.; Cottam, M.; McCandless, G.T.; Fronczek, F.R.; Vicente, M.G.H. Spectroscopic, computational modeling and cytotoxicity of a series of meso-phenyl and meso-thienyl-BODIPYs. Bioorg. Med. Chem. 2013, 21, 5770-5781. [CrossRef]

34. Swaminathan, S.; Fowley, C.; Raj Thapaliya, E.; McCaughan, B.; Tang, S.; Fraix, A.; Captain, B.; Sortino, S.; Callan, J.F.; Raymo, F.M. Supramolecular nanoreactors for intracellular singlet-oxygen sensitization. Nanoscale 2015, 7, 14071-14079. [CrossRef]

35. Zhou, J.; Zhang, Y.; Yu, G.; Crawley, M.R.; Fulong, C.R.P.; Friedman, A.E.; Sengupta, S.; Sun, J.; Li, Q.; Huang, F.; et al. Highly Emissive Self-Assembled BODIPY-Platinum Supramolecular Triangles. J. Am. Chem. Soc. 2018, 140, 7730-7736. [CrossRef]

36. LeBlanc, L.E.; Gibbs, J.H.; Vicente, M.G.H.; Fronczek, F.R. CCDC 972982: Experimental Crystal Structure Determination. 2013. [CrossRef]

37. Sabatini, R.P.; Lindley, B.; McCormick, T.M.; Lazarides, T.; Brennessel, W.W.; McCamant, D.W.; Eisenberg, R. Efficient Bimolecular Mechanism of Photochemical Hydrogen Production Using Halogenated Boron-Dipyrromethene (Bodipy) Dyes and a Bis(dimethylglyoxime) Cobalt (III) Complex. J. Phys. Chem. B 2016, 120, 527-534. [CrossRef]

38. Li, B.; Zang, S.-Q.; Wang, L.-Y.; Mak, T.C.W. Halogen bonding: A powerful, emerging tool for constructing high-dimensional metal-containing supramolecular networks. Coord. Chem. Rev. 2016, 308, 1-21. [CrossRef] 
39. Aakeroy, C.B.; Champness, N.R.; Janiak, C. Recent advances in crystal engineering. CrystEngComm 2010, 12, 22-43. [CrossRef]

40. Brammer, L.; Minguez Espallargas, G.; Libri, S. Combining metals with halogen bonds. CrystEngComm 2008, 10, 1712-1727. [CrossRef]

41. Metrangolo, P.; Pilati, T.; Terraneo, G.; Biella, S.; Resnati, G. Anion coordination and anion-templated assembly under halogen bonding control. CrystEngComm 2009, 11, 1187-1196. [CrossRef]

42. Saha, B.K.; Nangia, A.; Jaskólski, M. Crystal engineering with hydrogen bonds and halogen bonds. CrystEngComm 2005, 7, 355-358. [CrossRef]

43. Caronna, T.; Liantonio, R.; Logothetis, T.A.; Metrangolo, P.; Pilati, T.; Resnati, G. Halogen Bonding and $\pi \cdots \pi$ Stacking Control Reactivity in the Solid State. J. Am. Chem. Soc. 2004, 126, 4500-4501. [CrossRef] [PubMed]

44. Auffinger, P.; Hays, F.A.; Westhof, E.; Ho, P.S. Halogen bonds in biological molecules. Proc. Natl. Acad. Sci. USA 2004, 101, 16789-16794. [CrossRef] [PubMed]

45. Richards, V.J.; Gower, A.L.; Smith, J.E.H.B.; Davies, E.S.; Lahaye, D.; Slater, A.G.; Lewis, W.; Blake, A.J.; Champness, N.R.; Kays, D.L. Synthesis and characterisation of BODIPY radical anions. Chem. Commun. 2012, 48, 1751-1753. [CrossRef] [PubMed]

(C) 2020 by the authors. Licensee MDPI, Basel, Switzerland. This article is an open access article distributed under the terms and conditions of the Creative Commons Attribution (CC BY) license (http://creativecommons.org/licenses/by/4.0/). 